DOI: 10.12731/2070-7568-2017-3-177-189

УДК 338.24

\title{
УПРАВЛЕНИЕ ИНТЕЛЛЕКТУАЛЬНЫМ КАПИТАЛОМ ХОЗЯЙСТВУЮЩЕГО СУБЬЕКТА: ПОНЯТИЕ, ПРИНЦИПЫ, ВОЗНИКНОВЕНИЕ СИНЕРГЕТИЧЕСКОГО ЭФФЕКТА
}

\section{Устинова О.Е.}

Вопросы эффективного управления интеллектуальным капиталом хозяйствующих субъектов в современных условиях становятся особенно актуальными и требуют подробного изучения. С этой целью в данной статье приводится анализ основных научных подходов к управлению интеллектуальным капиталом, на основе которых уточнено его понятие. В работе рассматриваются общие управленческие принципь. Предыдущие исследования показывают, что в отношении принцииов управления интеллектуальным капиталом они рассматривались в основном с точки зрения системного подхода. На базе изученного материала выделены управленческие принципь, касаюшиеся движения интеллектуального капитала и его компонентов, в том числе человеческого, организационного и клиентского. Кроме того, обозначен синергетический эффект, появляюшийся в результате возникновения взаимосвязей и взаимодействия интеллектуальных и материальных ресурсов.

Ключевые слова: интеллектуальный капитал; принципы управления; синергетический эффект.

\section{MANAGEMENT OF INTELLECTUAL CAPITAL OF AN ECONOMIC ENTITY: THE CONCEPT, PRINCIPLES, THE EMERGENCE OF A SYNERGISTIC EFFECT}

\section{Ustinova O.E.}

The issues of effective management of intellectual capital of companies in modern conditions become especially urgent and require detailed study. To this end, this article analyzes the main scientific approaches to man- 
agement of intellectual capital, on the basis of which its clarified the definition. General principles of management are considered. Previous studies show that, with respect to the principles of management of intellectual capital, they were considered mainly from the point of view of a systematic approach. On the basis of the material studied, the principles concerning the movement of intellectual capital and its components, including human, organizational and client, are singled out. In addition, the synergetic effect that emerges as a result of the emergence of interrelations and the interaction of intellectual and material resources is indicated.

Keywords: intellectual capital; management principles; synergetic effect.

В современных экономических условиях интеллектуальный капитал приобретает стратегическое значение в развитии компаний, что служит основой повышения их конкурентоспособности. При этом актуальными становятся вопросы его эффективного управления. В этой связи возникает необходимость в изучении основных научных подходов к понятию «управление интеллектуальным капиталом», его принципов, а также возникновения синергетического эффекта, как невидимого актива, проявляющегося в результате взаимодействия интеллектуальных и материальных ресурсов.

Исследование научных работ зарубежных и отечественных ученых по данной проблематике показал, что управление интеллектуальным капиталом рассматривается с точки зрения системного подхода - как совокупности взаимосвязанных элементов (табл. 1).

Анализ научных подходов к определению термина «управление интеллектуальным капиталом» в современной научной литературе

Таблийа 1.

\begin{tabular}{|c|c|l|l|}
\hline $\begin{array}{c}\text { № } \\
\text { п/п }\end{array}$ & \multicolumn{1}{|c|}{ Автор } & \multicolumn{1}{|c|}{ Определение } & Ключевые слова \\
\hline & Й. Руус 12] & $\begin{array}{l}\text { ‥размещение и использование ресурсов } \\
\text { интеллектуального капитала, а также } \\
\text { управление ими и их трансформацией (в } \\
\text { другие ресурсы интеллектуального капи- }\end{array}$ & $\begin{array}{l}\text { размещение и } \\
\text { использование } \\
\text { ресурсов, их } \\
\text { трансформация } \\
\text { тала или традиционные ресурсы) с целью } \\
\text { максимизации текущей ценности органи- } \\
\text { зации в глазах заинтересованных сторон }\end{array}$ \\
\hline
\end{tabular}


Окончание табл. 1.

\begin{tabular}{|c|c|c|c|}
\hline 2 & $\begin{array}{l}\text { О.Н. Колпа- } \\
\text { кова [6] }\end{array}$ & $\begin{array}{l}\text { Процесс целенаправленного системати- } \\
\text { ческого воздействия на объект управле- } \\
\text { ния, представленного на первом уровне } \\
\text { в виде экономических субъектов рынка } \\
\text { или структур предприятия в процессах } \\
\text { функционирования интеллектуального } \\
\text { капитала, а на втором в виде их регули- } \\
\text { рования (самоорганизации) посредством } \\
\text { комплекса правовых, экономических и } \\
\text { социальных методов и способов воздей- } \\
\text { ствия, направленных на обеспечение эф- } \\
\text { фективного использования составляющих } \\
\text { интеллектуального капитала } \\
\end{array}$ & $\begin{array}{l}\text { процесс воздей- } \\
\text { ствия на объект, } \\
\text { регулирование } \\
\text { посредством } \\
\text { комплекса пра- } \\
\text { вовых, экономи- } \\
\text { ческих и соци- } \\
\text { альных методов } \\
\text { и способов }\end{array}$ \\
\hline 3 & $\begin{array}{l}\text { Ю.В. Кузне- } \\
\text { цов [8] }\end{array}$ & $\begin{array}{l}\text { Процесс руководства отдельным работ- } \\
\text { ником, рабочей группой и организацией } \\
\text { в целом }\end{array}$ & $\begin{array}{l}\text { процесс руко- } \\
\text { водства }\end{array}$ \\
\hline 4 & $\begin{array}{l}\text { И.А. Ива- } \\
\text { нюк [5] }\end{array}$ & $\begin{array}{l}\text { Система производственных отношений, } \\
\text { возникающих на уровне индивидуально- } \\
\text { го воспроизводства между субъектами } \\
\text { хозяйствования по поводу производства, } \\
\text { распределения и потребления интеллек- } \\
\text { туального продукта...как подсистема } \\
\text { экономической системы воспроизводства } \\
\text { капитала }\end{array}$ & $\begin{array}{l}\text { система отноше- } \\
\text { ний по поводу } \\
\text { производства, } \\
\text { распределения } \\
\text { и потребления } \\
\text { интеллектуаль- } \\
\text { ного продукта }\end{array}$ \\
\hline 5 & $\begin{array}{l}\text { Г.Б. Клей- } \\
\text { нер Г.Б., } \\
\text { В.Л. Мака- } \\
\text { ров [9] }\end{array}$ & $\begin{array}{l}\text {...единая взаимодействующая система, } \\
\text { обменивающаяся знаниями, информа- } \\
\text { цией, интеллектуальными ресурсами и } \\
\text { продуктами }\end{array}$ & $\begin{array}{l}\text { система, обме- } \\
\text { нивающаяся } \\
\text { знаниями, } \\
\text { информацией, } \\
\text { ресурсами и } \\
\text { продуктами }\end{array}$ \\
\hline 6 & $\begin{array}{l}\text { С.В. По- } \\
\text { кровский } \\
{[11]}\end{array}$ & $\begin{array}{l}\text {... действия по увеличению не только } \\
\text { стоимости, но и результативности интел- } \\
\text { лектуального капитала }\end{array}$ & $\begin{array}{l}\text { действия по } \\
\text { увеличению сто- } \\
\text { имости и резуль- } \\
\text { тативности }\end{array}$ \\
\hline 7 & $\begin{array}{l}\text { Т.А. По- } \\
\text { горельская } \\
{[12]}\end{array}$ & $\begin{array}{l}\text {...умение привлекать, создавать и ис- } \\
\text { пользовать интеллектуальный капитал в } \\
\text { хозяйственной деятельности с целью при- } \\
\text { роста стоимости бизнеса и укрепления } \\
\text { конкурентных позиций }\end{array}$ & $\begin{array}{l}\text { умение привле- } \\
\text { кать, создавать и } \\
\text { использовать }\end{array}$ \\
\hline
\end{tabular}

Для формирования эффективных моделей и организационных форм управления интеллектуальным капиталом необходимо обозначить принципиальные требования, которые позволят достичь поставленных целей. При этом важно подчеркнуть, что в научном сооб- 
ществе не сложилось единого подхода к классификации принципов управления, также отсутствует единство по поводу содержания его базовых принципов. Некоторые из них, по содержанию, являются правилами поведения, а другие вытекают из основных и становятся производными. В этой связи из всей совокупности принципов к числу общих следует отнести принципы научности, единства теории и практики управления, непрерывности управления, диалектичности, законности. Среди структурно-функциональных стоит выделить принципы унификации элементов системы, функциональной специализации в сочетании с универсализацией, последовательности управленческих решений, комплексности, иерархии и обратной связи, единства прав и ответственности, единоначалия и коллегиальности и другие. Таким образом, с позиций системного подхода эффективный набор принципов представляет собой систему, включающую как сами принципы, так и взаимосвязи между ними. Вместе с тем, цель существования этой системы будет характеризоваться свойством эмерджентности: «появление новых свойств и качеств системы, не присущие ее исходным элементам» [10]. Учитывая цели исследования целесообразно прокомментировать ряд управленческих принципов применительно к решению задач по повышению эффективности управления интеллектуальным капиталом (табл. 2).

\section{Принципы управления интеллектуальным капиталом хозяйствующих субъектов}

Таблицุа 2.

\begin{tabular}{|c|c|l|l|}
\hline \multicolumn{2}{|c|}{ № п/п } & \multicolumn{1}{|l|}{ Принципы } & \multicolumn{1}{|c|}{ Управление интеллектуальным капиталом } \\
\hline \multirow{2}{*}{1} & $\begin{array}{l}\text { Принцип } \\
\text { научной обо- } \\
\text { снованности }\end{array}$ & $\begin{array}{l}\text { Подразумевает, что управление интеллектуальным } \\
\text { капиталом в части его формирования, развития и } \\
\text { использования должно базироваться на передовом } \\
\text { опыте практиков и научно-обоснованных положений, } \\
\text { на установлении объективных связей всех элементов } \\
\text { исследуемой области и взаимодействия с другими ка- } \\
\text { тегориями. }\end{array}$ \\
\hline 2 & $\begin{array}{l}\text { Принцип } \\
\text { диалектич- } \\
\text { ности }\end{array}$ & $\begin{array}{l}\text { Предполагает рассмотрение процессов формирования, } \\
\text { развия и использования интеллектуального капитала } \\
\text { в динамике как циклы движения. }\end{array}$ \\
\hline
\end{tabular}




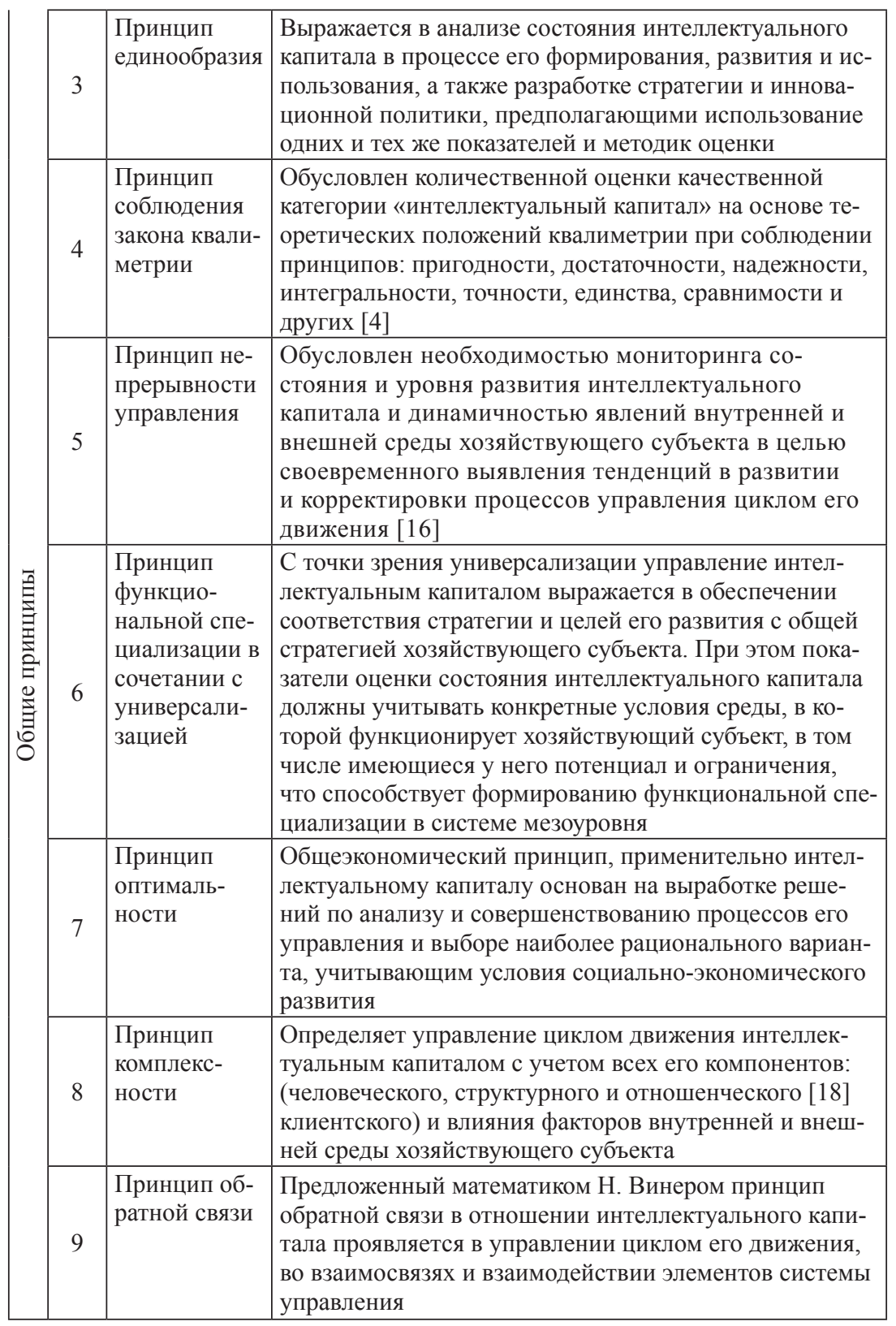


Окончание табл. 2.

\begin{tabular}{|c|c|c|c|}
\hline \multirow{6}{*}{ 目 } & 10 & $\begin{array}{l}\text { Принцип де- } \\
\text { композиции }\end{array}$ & $\begin{array}{l}\text { Предполагает разделение сложных явлений и про- } \\
\text { цессов на более простые в целях исследования их } \\
\text { сущности с дальнейшим воссозданием системы ка } \\
\text { единого целого [7]. Целесообразно применение метода } \\
\text { декомпозиционного моделирования с использованием } \\
\text { логических, графических и цифровых моделей }\end{array}$ \\
\hline & 11 & $\begin{array}{l}\text { Принцип } \\
\text { моделируе- } \\
\text { мости }\end{array}$ & $\begin{array}{l}\text { Важен при управлении инновационных систем, про- } \\
\text { являющийся в необходимости построения модели } \\
\text { управления интеллектуальным капиталом на уровне } \\
\text { предприятия [15] }\end{array}$ \\
\hline & 12 & $\begin{array}{l}\text { Принцип } \\
\text { эмерджент- } \\
\text { ности }\end{array}$ & $\begin{array}{l}\text { Предполагает возникновение у хозяйствующего субъ- } \\
\text { екта в целом особых свойств и характеристик (на- } \\
\text { пример, корпоративный имидж, деловая репутация) в } \\
\text { связи с формированием, развитием, распределением } \\
\text { и использованием компонентов интеллектуального } \\
\text { капитала }\end{array}$ \\
\hline & 13 & $\begin{array}{l}\text { Принцип } \\
\text { согласован- } \\
\text { ности }\end{array}$ & $\begin{array}{l}\text { Принцип согласованности [3] проявляется во взаи- } \\
\text { модействии между иерархическими звеньями хозяй- } \\
\text { ствующих субъектов и отдельными их элементами } \\
\text { по горизонтами, учитывая основные цели развития } \\
\text { интеллектуального капитала }\end{array}$ \\
\hline & 14 & $\begin{array}{l}\text { Принцип } \\
\text { синергизма }\end{array}$ & $\begin{array}{l}\text { Выражается в проявлении [4] синергетического эффек- } \\
\text { та, возникающего в результате взаимосвязей и взаимо- } \\
\text { действия интеллектуальных и материальных ресурсов }\end{array}$ \\
\hline & 15 & $\begin{array}{l}\text { Принцип } \\
\text { концентра- } \\
\text { ции знаний } \\
\text { на ключевых } \\
\text { компетен- } \\
\text { циях }\end{array}$ & $\begin{array}{l}\text { Обусловлен функционированием хозяйствующего } \\
\text { субъекта в определенной отрасли и фокусированием } \\
\text { знаний, присущих ей. «Способность трансформи- } \\
\text { ровать знания и нематериальные активы в факторы } \\
\text { (ресурсы), которые создают богатство (и соответству- } \\
\text { ющую стоимость) за счет особого эффекта от «умно- } \\
\text { жения» человеческого капитала на структурный» [17] }\end{array}$ \\
\hline
\end{tabular}

Таким образом, систему принципов управления интеллектуальным капиталом хозяйствующего субъекта целесообразно выстраивать на основе общих принципов формирования и развития систем управления с включением основных компонентов интеллектуального капитала, а также базовых принципов концепции управления персоналом и кибернетики в менеджменте (рис. 1), важной частью которых могут стать: 
- Принцип синергии материальных и интеллектуальных ресурсов, проявляющийся в процессах формирования, развития и использования интеллектуального капитала и оказывающий позитивное влияние на экономические показатели и эффективность деятельности хозяйствующего субъекта в целом.

- Принцип равноправного доступа всех элементов хозяйствующей системы к объектам интеллектуального капитала, предполагающий обеспечение тесного взаимодействия и сотрудничества заинтересованных лиц в инновационной деятельности;

- Принцип приоритета стратегически важных целей в управлении интеллектуальным капиталом, означающий эффективное сочетание процессов формирования, развития и использования всех его компонентов (человеческого, структурного, клиентского), избегая при этом усиления внимания к одному из них в ущерб другим.

Принципы формирования и развития систем управления персоналом:

Согласованности; перспективности; автономности и централизации; прозрачности; комфортности; адаптивности; преемственности; оптимальности; согласованности

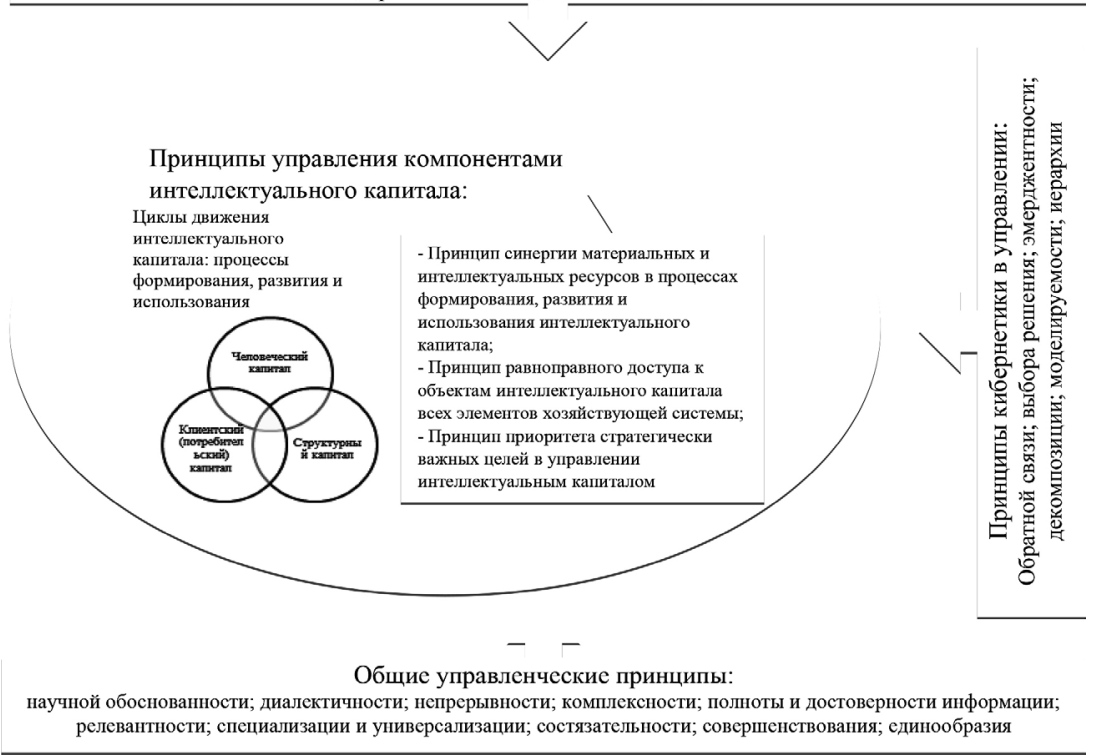

Рис. 1. Система принципов управления интеллектуальным капиталом 
Анализ научных подходов к определению термина «управление интеллектуальным капиталом» и рассмотренные выше принципы позволили сформулировать его как процесс воздействия субъектом на ресурсы организации, направленный на получение синергетического эффекта, проявляющийся как результат возникновения взаимосвязей и взаимодействия компонентов интеллектуального капитала, материальных и финансовых ресурсов, ориентированный на повышение конкурентоспособности и максимизацию ценности хозяйствующего субъекта.

Выбор и точное обозначение принципов управления интеллектуальным капиталом хозяйствующего субъекта является основой достижения его стратегических целей. В этой связи заслуживает внимания выдающийся вклад Питера Сенге и его ключевые положения концепции для практики интеллектуального предпринимательства, к которым следует отнести: обучение в команде, а также обучение способности находить общее стратегическое видение успешного будущего компании и адекватным способам его достижения [20]. Следствием этого станет появления синергетического эффекта. Исследование синергизма прежде всего связано с его применением в качестве универсальной категории в разных аспектах - естественнонаучном, философском, математическом, социальном и экономическом. Таким образом, синергетический эффект является следствием действия различных факторов, направленных на его получение в результате их эффективного комбинирования и взаимодействия. Считается, что в основой появления синергетического эффекта является наличие нелинейной динамики развития объектов системы [2]. Само формирование синергизма обусловлено одновременным использованием ресурсов хозяйствующего субъекта в нескольких областях деятельности. Считается, что синергизм появляется в виде комплементарного эффекта (франц. compleément - дополнение), позволяющего комбинировать различные ресурсы хозяйствующих субъектов, в том числе материальных, интеллектуальных, финансовых, и соответственно формировать конкурентное преимущество. При этом невидимые активы могут быть использованы одновременно и многократно. В этой связи особое внимание заслуживает 
информация, обладающая свойствами и вызывающая синергетический эффект: пользование ею одновременно несколькими субъектами, комбинирование ее составными частями, позволяющее получить новый продукт.

Само понятие синергизма стало формироваться с середины прошлого столетия. Тем не менее, обращаясь к истории необходимо выделить работу О.А. Ерманского [4] «Теория и практика рационализации». Автор обосновал принцип организации, в соответствии с которым организационная сумма больше арифметической суммы сил ее составляющих. Обращаясь к концепции И. Ансоффа о синергизме («Синергизм и ресурсы» из опубликованной в 1965 г. работы «Корпоративная стратегия») видно, что его обоснование основывается на эффекте, «способном продуцировать уровень выручки интегрированной компании, превышающий сумму аналогичных показателей функционирующих по отдельности ее дивизионов» [1]. Понятие «комплементарный (дополняющий) эффект» вводит $\mathrm{X}$. Итами. С соответствии с его теорией «возникновению эффекта способствует сосуществование двух несвязанных элементов стратегии» [19]. Отсюда следует, что синергетическая эффективность является характерной чертой жизнеспособности хозяйствующего субъекта и основой его успешного функционирования (рис. 2).

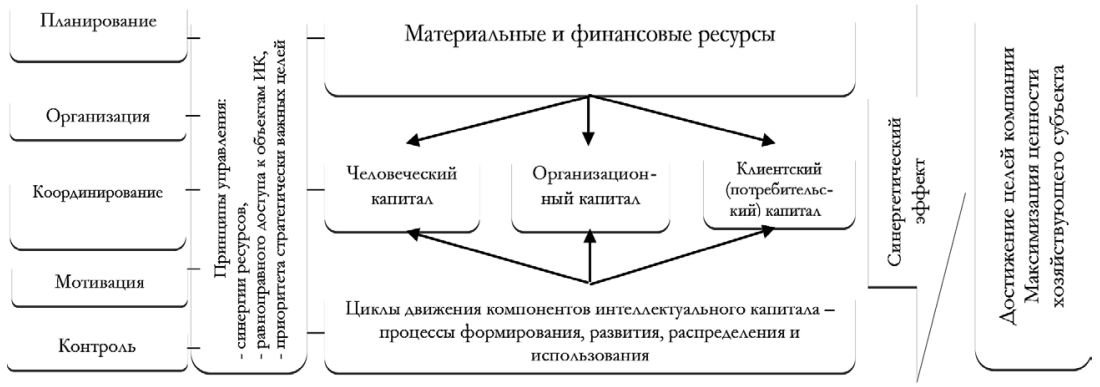

Рис. 2. Управление интеллектуальным капиталом хозяйствующего субъекта

При этом до сих пор остается открытым вопрос измерения данного эффекта, применительно к интеллектуальному капиталу и его компонентам. 
Управление интеллектуальным капиталом по стадиям цикла его движения, а также взаимодействия с другими ресурсами должно учитывать влияние факторов внешней и внутренней среды хозяйствующего субъекта. Это служит основой для более объективной оценки состояния компонентов интеллектуального капитала и создает условия для их формирования, эффективного распределения, использования и развития. В результате исследования выделены управленческие принципы, относящиеся к движению интеллектуального капитала и его компонентамов, в том числе человеческого, организационного и клиентского. В рамках цикла движения обозначен синергетический эффект, проявляющийся как результат взаимосвязей и взаимодействия интеллектуальных и материальных ресурсов. Исследование научных работ зарубежных и отечественных ученых в отношении определения термина «управление интеллектуальным капиталом» рассматривается с точки зрения системного подхода - как совокупности взаимосвязанных элементов. В рамках данной работы уточнено его понятие во взаимосвязи с синергетическим эффектом на основе предложенных принципов управления. Результаты исследования в дальнейшем могут быть использованы для формирования модели экономической оценки влияния интеллектуального капитала на конкурентоспособность хозяйствующих субъектов.

\section{Список литературы}

1. Ансофф И. Новая корпоративная стратегия. СПб: Издательство «Питер». 199. 416 с.

2. Гунина Е.Н. Стратегия достижения синергии интеграционного взаимодействия отдельных юридических лиц в рамках деятельности крупных корпоративных структур // Экономический вестник Ростовского государственного университета. 2007. Т. 5. № 3. С. 53-58.

3. Гранберг А.Г. Движение регионов России к инновационной экономике / Под ред. А.Г. Гранберга, С.Д. Валентен. Институт экономики РАН. М.: Наука, 2006. С. 171-186.

4. Ерманский О.А. «Теория и практика рационализации / О.А. Ерманский. Т.1. М.-Л., 1930. [Электронный ресурc]. URL: http:// www. malb.ru/literatura/racionalizacia.html. 
5. Иванюк И.А. Воспроизводство интеллектуального капитала в современных маркетинг-системах [Электронный ресурс]. URL: http:// cis2000.ru/Budgeting/IntelectCapitalUp.shtml

6. Колпакова О.Н. Интеллектуальный капитал и интеллектуальная собственность в инновационной экономике. Монография. М.: Палеотип, 2005.

7. Колпакова О.Н. Принципы управления интеллектуальным капиталом в инновационной экономике // Инновации и инвестиции. 2008. № 4.

8. Кузнецов Ю.В. Менеджмент: учебник / Под ред. проф. Ю.В. Кузнецова; СПбГУ, экон. факультет, 2010. 503 с.

9. Макаров В.Л., Клейнер Г.Б. Микроэкономика знаний. М: Экономика, 2007. 204 с.

10. Никоноров В.М. Классификация систем для управления / В.М. Никоноров // Наука Красноярья. 2016. № 5(38). С. 146-160.

11. Покровский С.В. Определение сущности интеллектуального капитала // Четвертая межвуз. науч.-практ. конф. молодых ученых по актуальным вопросам менеджмента и бизнеса. Т.1. М.: Изд-во Национального института бизнеса, 2005.

12. Погорельская Т.А. Интеллектуальный капитал промышленных предприятий. Организационно-экономические механизмы формирования и использования / LAP LAMBERT Academic Publishing. 2001. 188 c.

13. Руус Й. Интеллектуальный капитал: практика управления / Й. Руус, С. Пайк, Л. Фернстрем; пер. с анг. под ред. В.К. Дерманова. 2-е изд. СПб.: Высшая школа менеджмента, 2008. 436 с.

14. Степанова А.Е. Интеллектуальный капитал как фактор развития инновационной экономики: дис. ...канд. экон. наук: 08.00.05 / А.Е. Степанова. Ставрополь, 2010. 154 с.

15. Фасхиев Х.А., Крахмалева А. Инновационный инструмент управления конкурентоспособностью // Менеджмент инноваций. 2014. № 4.

16. Фасхиев Х.А. Интеллектуальный капитал - основа инновационного развития предприятия // Инновации. 2011. № 6. С. 31-43.

17. Эдвинссон Л. Корпоративная долгота. Навигация в экономике, основанной на знаниях. М.: ИНФРА-М, 2005. 252 с.

18. Bontis N. National Intellectual Capital Index: a United Nations initiative for the Arab region // Journal of Intellectual Capital. 2004. № 1, pp. 13-39. 
19. Itami H., Roehl T.W. Mobilizing Invisible Assets. Cambridge, Massachusetts and London: Harvard University Press, 1991. 200 p.

20. Senge P. The Fifth Discipline: The Art and Practice of The Learning Organization. New York: Doubleday / Currency, 1990.

\section{References}

1. Ansoff I. Novaya korporativnaya strategiya [New corporate strategy]. $\mathrm{SPb}$ : Izdatel'stvo «Piter». 199. 416 p.

2. Gunina E.N. Ekonomicheskiy vestnik Rostovskogo gosudarstvennogo universiteta. 2007. V. 5. № 3, pp. 53-58.

3. Granberg A.G. Dvizhenie regionov Rossii k innovatsionnoy ekonomike [Movement of Russian regions to the innovation economy]. M.: Nauka, 2006, pp. 171-186.

4. Ermanskiy O.A. Teoriya i praktika ratsionalizatsii [Theory and practice of rationalization]. V.1. M.-L., 1930. http://www.malb.ru/literatura/racionalizacia.html

5. Ivanyuk I.A. Vosproizvodstvo intellektual'nogo kapitala v sovremenny$k h$ marketing-sistemakh [Reproduction of intellectual capital in modern marketing systems].http://cis2000.ru/Budgeting/IntelectCapitalUp.shtml

6. Kolpakova O.N. Intellektual'nyy kapital i intellektual'naya sobstvennost' $v$ innovatsionnoy ekonomike [Intellectual capital and intellectual property in the innovation economy]. M.: Paleotip, 2005.

7. Kolpakova O.N. Innovatsii i investitsii. 2008. № 4.

8. Kuznetsov Yu.V. Menedzhment [Management]; SPbGU, ekon. fakul'tet, 2010. 503 p.

9. Makarov V.L., Kleyner G.B. Mikroekonomika znaniy [Microeconomics of knowledge]. M: Ekonomika, 2007. 204 p.

10. Nikonorov V.M. Nauka Krasnoyar ’ya. 2016. № 5(38), pp. 146-160.

11. Pokrovskiy S.V. Chetvertaya mezhvuz. nauch.-prakt. konf. molodykh uchenykh po aktual'nym voprosam menedzhmenta i biznesa [Fourth interuniversity. scientific-practical. Conf. young scientists on topical issues of management and business]. V.1. M.: Izd-vo Natsional'nogo instituta biznesa, 2005.

12. Pogorel'skaya T.A. Intellektual'nyy kapital promyshlennykh predpriyatiy. Organizatsionno-ekonomicheskie mekhanizmy formirovaniya $i$ 
ispol'zovaniya [Intellectual capital of industrial enterprises. Organizational-economic mechanisms of formation and use] / LAP LAMBERT Academic Publishing. 2001. 188 s.

13. Ruus Y. Intellektual'nyy kapital: praktika upravleniya [Intellectual Capital: Practice of Management] / Y. Ruus, S. Payk, L. Fernstrem. SPb.: Vysshaya shkola menedzhmenta, 2008. $436 \mathrm{p}$.

14. Stepanova A.E. Intellektual'nyy kapital kak faktor razvitiya innovatsionnoy ekonomiki [Intellectual capital as a factor in the development of innovative economy]. Stavropol', 2010. 154 p.

15. Faskhiev Kh.A., Krakhmaleva A. Menedzhment innovatsiy. 2014. № 4.

16. Faskhiev Kh.A. Innovatsii. 2011. № 6, pp. 31-43.

17. Edvinsson L. Korporativnaya dolgota. Navigatsiya v ekonomike, osnovannoy na znaniyakh [Corporate Longitude. Navigation in an economy based on knowledge]. M.: INFRA-M, 2005. 252 p.

18. Bontis N. National Intellectual Capital Index: a United Nations initiative for the Arab region. Journal of Intellectual Capital. 2004. № 1, pp. 13-39.

19. Itami H., Roehl T.W. Mobilizing Invisible Assets. Cambridge, Massachusetts and London: Harvard University Press, 1991. 200 p.

20. Senge P. The Fifth Discipline: The Art and Practice of The Learning Organization. New York: Doubleday / Currency, 1990.

\section{ДАННЫЕ ОБ АВТОРЕ}

Устинова Ольга Евгеньевна, кандидат экономических наук, доцент Московская академия Следственного комитета Российской Федерачии

ул. Врубеля, 12, г. Москва, 125080, Российская Федерация olga.e.ustinova@yandex.ru

\section{DATA ABOUT THE AUTHOR}

Ustinova Olga Evgenievna, Candidate of Economic Sciences, Associate Professor

Moscow Academy of the Investigative Committee of the Russian Federation

12, Vrubel Str., Moscow, 125080, Russian Federation

olga.e.ustinova@yandex.ru 